\title{
АНАЛИЗ ПРИМЕНИМОСТИ ЗАРУБЕЖНОГО ОПЫТА ОРГАНИЗАЦИИ ПРИГОРОДНЫХ ЖЕЛЕЗНОДОРОЖНЫХ ПЕРЕВОЗОК В РОССИИ
}

\section{THE APPLICABILITY OF FOREIGN EXPERIENCE OF ORGANIZING SUBURBAN RAIL TRANSPORT IN RUSSIA}

\section{G. Filichev}

Summary. The article is devoted to the analysis of the applicability of foreign experience in the organization of suburban rail transportation in Russia. The author noted that in modern conditions of the functioning of the market and the development of public processes, railroad suburban transport has better performance than competitors, which makes it the most socially oriented and safe. In this regard, the industry should reorganize its work in a certain volume of transportation with the simultaneous implementation of measures that reduce the negative impact on society and the environment, which is typical for sustainable development. The author also focuses on the fact that the reorganization concerns, first of all, the administrative structure of the Russian railway. To implement the management functions in rail transport, foreign countries use various organizational models (organizational structures) of management or the form of distribution of functions between the links and the management structure, indicating the composition and mutual subordination of these links, which are studied in this paper.

Taking into account the results of the analysis of the possibilities of continuity of the experience of foreign countries in reforming and developing mechanisms, methodologies and strategies for organizing suburban rail transportation in Russia, the author determined that the improvement of the existing system of domestic passenger traffic control in suburban communication can be implemented by:

- development of scientific principles and research concepts for building management models;

- theoretical and methodological approach to comparing different organizational models of passenger transportation management.

Keywords: suburban transportation, railway transport, organization, management, foreign experience, improvement.

\section{Постановка проблемы}

$\Pi$ ассажирские перевозки в пригородном сообщении в современных условиях развития сферы железнодорожного транспорта являются массовыми и наиболее доступными для населения, а, следовательно, имеют высокую социальную значимость. Актуальность данного исследования заключается
Филичев Григорий Андреевич

Доктор государственного управления - Doctor of Public Administration (DPA), Российская академия народного хозяйства и государственной службы при Президенте РФ gfilichev@gmail.com

Аннотация. Статья посвящена проведению анализа применимости зарубежного опыта организации пригородных железнодорожных перевозок в России. Автором отмечено, что в современных условиях функционирования рынка и развития общественных процессов железнодорожный пригородный транспорт имеет лучшие показатели по сравнению с конкурентами, что делает его наиболее социально направленным и безопасным. В связи с этим отрасль должна реорганизовать свою работу в определенном объеме перевозок с одновременной реализацией мероприятий, которые уменьшают негативное влияние на общество и окружающую среду, что характерно для устойчивого развития. Также автором в работе акцентировано внимание на том, что реорганизация касается, прежде всего, управленческой структуры железной дороги России. Для реализации функций управления на железнодорожном транспорте зарубежные страны используют различные организационные модели (организационные структуры) управления или формы распределения функций между звеньями и структурой управления с указанием состава и взаимной подчиненности этих звеньев, которые исследованы в данной работе.

С учетом результатов проведенного анализа возможностей преемственности опыта зарубежных стран в реформировании и развитии механизмов, методологий и стратегий организации пригородных железнодорожных перевозок в России, автором определено, что усовершенствование существующей системы отечественного управления пассажирскими перевозками в пригородном сообщении может быть реализовано за счет:

- $\quad$ разработки научных принципов и исследовательских концепций построения моделей управления;

- теоретико-методического подхода к сравнению между собой различных организационных моделей управления пассажирскими перевозками.

Ключевые слова: пригородные перевозки, железнодорожный транспорт, организация, управление, зарубежный опыт, совершенствование.

в том, что накопленный отечественный и зарубежный опыт работы по совершенствованию организации пригородных пассажирских железнодорожных перевозок свидетельствует о необходимости применения новых организационных и технологических решений в управлении перевозками. Для рационального использования пассажирского подвижного состава и повышения удобств, комфорта пассажиров на железных дорогах 
России нужно постоянно проводить исследования плотности использования вагонов в поездах пригородного сообщения в зависимости от сезонности, уровня сервиса, качества предоставляемых услуг, а также интервала отправления и дальности перевозок пассажиров. Дальнейшее увеличение перевозок требует формирования нового уровня транспортного обеспечения потребностей экономики и общества. Однако на сегодняшний день технология пригородных перевозок происходит без учета существующего колебания спроса на перевозки, который может меняться.

Основная задача организации пригородных пассажирских перевозок заключается в достижении максимальной эффективности функционирования пригородного пассажирского транспорта, обеспечении полного и качественного удовлетворения спроса населения на перевозки с оправданным уровнем затрат. Одним из основных направлений развития организации пригородных пассажирских перевозок является формирование и дальнейшее совершенствование концепции на основании положительного опыта реформирования вопросов зарубежными странами. Цель данной статьи - обосновать направление совершенствования технологии пригородных пассажирских железнодорожных перевозок за счет определения возможностей реформирования направления на основании анализа зарубежного опыта.

\section{Из^ожение основного материа^а исслеАОваний с обоснованием научных результатов}

Система организации пригородных пассажирских перевозок рассматривается как одна из составляющих единой системы пассажирского транспорта. На железнодорожном транспорте система организации перевозок в большинстве стран является поэтапной. На первом этапе устанавливается ожидаемый объем перевозок на основных направлениях и участках, на втором - выбирается оптимальный план формирования составов пригородных поездов, затем составляется схема оборота составов на полигонах сети и разрабатывается график пассажирского движения [5].

Размеры движения пригородных поездов в значительной степени определяют качество и эффективность перевозочного процесса, поскольку с одной стороны с ними связаны условия проезда пассажиров, а с другой - потребность в подвижном составе, необходимая пропускная способность. Учитывая убыточность пригородных пассажирских перевозок и высокую себестоимость, необходимость избегания в перспективе «перекрестного субсидирования», количество поездов должно соответствовать величине и структуре приго- родных пассажиропотоков, техническим возможностям депо, владельцев и операторов подвижного состава, направлений и станций [4].

Существует ряд научных трудов и разработок, касающихся реструктуризации и развития пассажирских перевозок. Например, С. Рахман в соавторстве с С. Балиджепалли [13] в рамках опыта Индии рассматривает реструктуризацию как организационно-экономические, правовые, технические мероприятия, направленные на изменение структуры предприятия, его управления, форм собственности, организационно-правовых форм, которые способны привести предприятие железнодорожной сферы к финансовому оздоровлению. Таким образом, признается направленность реструктуризации пассажирских перевозок на оздоровление и рост конкурентоспособности.

Исследователи Ли Х., Ян Т. и Ши К., рассматривая опыт Китая, для повышения эффективности пассажирских перевозок предлагает использовать методы логистики и стратегического маркетинга [11]. В своей работе он констатирует, что весь процесс управления пассажиропотоками с начала образования и до момента завершения является единственным логистическим звеном, который может дополняться информационными, сервисными и другими потоками. Также автор приводит схему логистической предпринимательской системы обработки пассажирских потоков, с помощью которой предлагается повысить эффективность пассажирских перевозок. Пассажирский комплекс, по его мнению,это сложная, условно дискретная, динамично открытая (детерминировано-вероятная) логистическая система, построенная из взаимосвязанных элементов. Для пассажирского комплекса автор предлагает схему взаимозависимости отдельных операций, которая при дифференциации пригородного пассажиропотока позволит уменьшить количество остановок дальних электропоездов в пригородной зоне и, как следствие, увеличить скорость перевозок пассажиров в пригородном сообщении, а также сэкономить значительное количество энергоносителей [11].

Х. Ким, С. Султана и Дж. Вебер в контексте исследования данных по железнодорожным пригородным перевозкам Кореи предлагают определить график изменения пассажиропотоков на маршруте следования с учетом особенностей направления движения каждого пригородного поезда и факторы, влияющие на величину пассажиропотока для каждого региона. Такой подход позволит более обоснованно организовывать систему определения себестоимости перевозок пассажиров и тарифов в пригородном сообщении, оптимизировать длину и график движения пригородных поездов [10]. 
Результаты исследования динамики развития пригородного скоростного движения на зарубежных железных дорогах, представлены в работах Чжоу Л., Лю Ю, Лю Ин [14]. Авторы сделали вывод, что развитие пригородного скоростного движения на зарубежных железных дорогах происходит в трех направлениях:

- повышение скоростей на существующих железных дорогах за счет усиления верхнего строения пути и совершенствования конструкции подвижного состава (Великобритания, Германия и некоторые другие страны);

- строительство специальных скоростных магистралей, изолированных от остальной части сети (Япония);

- строительство специальных высокоскоростных линий, имеющих пункты стыковки с существующей сетью (Италия, Франция).

Высокоскоростное движение пассажирских поездов является альтернативной системой относительно сфер авиации и автомобилей. Следует отметить также работу Агафонова Д.В. [1], в которой автор подчеркивает, что повышение качества обслуживания пассажиров, увеличение доходов от пассажирских перевозок, снижения эксплуатационных расходов являются главными задачами железнодорожного транспорта Российской Федерации.

В результате реформ железнодорожного транспорта стран СНГ и Балтии наблюдается устойчивая тенденция вывода железных дорог из государственного сектора экономики. В Армении, Грузии, Казахстане, Узбекистане, Латвии, Литве, Эстонии, а также в России, реформирование осуществляется путем акционирования государственных железных дорог [6].

Важный шаг в изменении структуры управления использование дивизионной организации в управлении транспортом (опыт США, Канады и Мексики): отказ от ориентации только на продукт и национальные границы. Расширение границ структурирования позволяет перейти от узконационального интереса к пониманию того, что железные дороги должны действовать на общем рыночном пространстве, ориентируясь при этом на международные перспективы и участие в совместной конкурентной борьбе с автомобильным и прочим транспортом. Создание таких организационных структур - одна из главных задач стран-участниц ЕС. Поэтому идет поиск новых путей управления железнодорожным транспортом [7].

Реформирование железнодорожного транспорта Швеции направлено на создание условий для деятельности железных дорог на коммерческой основе и проходит в четыре этапа: 1-й этап: рационализация управления; сокращение штата кадров сферы.

2-й этап: совершенствование организационной структуры управления (профит-центры, бизнес-сектора, новая система бухгалтерского учета); разрешение доступа к сети управления железнодорожным транспортом.

3-й этап: повышение качества обслуживания клиентов.

4-й этап: качественное развитие железных дорог (развитие инфраструктуры, подвижного состава) [9].

Особый интерес вызывает транспортная политика Швеции, основные положения которой следующие:

1. Все виды транспорта в конкурентной борьбе должны быть в равных условиях.

2. Разграничение функций управления.

3. Государство берет на себя содержание транспортных сетей.

4. Сборы за оказанные транспортные услуги должны покрывать расходы на содержание.

5. Налоги на сборы не должны ставить один вид транспорта в привилегированное положение по отношению к другому.

Рассматривая отрасль пригородных железнодорожных перевозок в России следует отметить, что Федеральным законодательством ответственность за организацию транспортного обслуживания населения пригородным железнодорожным транспортом возложена на субъекты Российской Федерации (в т.ч. в части определения уровня тарифа для пассажира и компенсации возникающих потерь в доходах перевозчика вследствие тарифного регулирования за счет средств регионального бюджета). Основные принципы организации пригородных перевозок, а также модель регионального заказа, сформулированы и утверждены в Концепции развития пригородных пассажирских перевозок железнодорожным транспортом (утверждена распоряжением Правительства Российской Федерации от 19 мая 2014 г. № 857-р) [17]. Также в рамках развития транспортной отрасли в стране принята и полноценно реализуется Транспортная стратегия РФ на период до 2030 года [15].

Проблематика реализации эффективного уровня Стратегии обосновывается тем, что не всеми субъектами страны выполняются установленные положения, из чего следует продуцирование фундаментальной проблемы пригородного комплекса - недофинансирования перевозок. При этом сохраняется проблема дефицита региональных бюджетов, которая является сдерживающим фактором в обеспечении всех потребностей в пригородных железнодорожных перевозках [16]. Эта проблема 
должна решаться совместно с Федеральными органами власти в лице Министерства Финансов Российской Федерации путем определения порядка формирования сбалансированности бюджетов дотационных регионов, в том числе за счет межбюджетных трансфертов. В противном случае проблемы будут только усугубляться. Одновременно, в целях снижения потребного размера субсидий субъектами Российской Федерации принимаются решения по увеличению уровня тарифов для населения и оптимизации размеров движения пригородных поездов. При этом значительная часть малонаселенных пунктов, обслуживаемых железной дорогой, не имеет альтернативных видов сообщения, что приводит к ухудшению транспортной обеспеченности населения. В результате снижения объемов транспортной работы затронутыми также оказываются и смежные компании - заводы по производству вагонов электропоездов, вследствие вынужденного уменьшения объема закупок новых вагонов, и заводы, осуществляющие капитальный ремонт парка электропоездов [3].

Убыточность деятельности перевозчиков помимо угрозы банкротства компаний ведет и к еще одной серьезной проблеме: росту дебиторской задолженности ОАО «РЖД». В связи с тем, что пригородные пассажирские компании являются отдельными юридическими лицами и не имеют дополнительных источников для покрытия убытков от перевозочной деятельности, то при отсутствии государственной поддержки основные риски продолжает нести ОАО «РЖД» (как основной поставщик услуг для перевозчиков). Соответственно, ОАО «РЖД» вынуждено отвлекать собственные денежные средства для оплаты труда машинистов, обслуживающих пригородные поезда, счетов на электроэнергию, что проводит к необходимости дополнительного привлечения компанией заемных средств из внешних источников для финансирования своей текущей деятельности, и, как результат, увеличению процентов к уплате, что негативно сказывается на финансовом результате, особенно в условиях складывающейся негативной макроэкономической обстановки. Таким образом, убыточность пригородного комплекса оказывает серьезное отрицательное влияние на деятельность всего железнодорожного транспорта в Российской Федерации [2].

Вопросы соотношения частной и государственной собственности решаются в разных странах неодинаково. В нашей стране особенно популярен вопрос о необходимости обновления организационно-правовой формы акционирования на железной дороге. Его актуальность обусловлена социально-политическими условиями, которые изменились в последние десятилетия. Прежде чем кардинально решать вопрос о собственности, следует согласиться, что оба варианта (частные и государственные железные дороги) имеют положительные и от- рицательные стороны. В пользу приватизации железных дорог свидетельствует тот факт, что опыт зарубежных стран отражает следующее: частные железные дороги, в отличие от государственных, направляют свою производственно-хозяйственную деятельность на получение прибыли путем диверсификации деятельности, агрессивности и жесткости, более эффективного использования основных фондов и трудовых ресурсов, гибкости и скорости действий на рынке товаров и услуг. Однако приватизация железных дорог возможна только в том случае, если они будут привлекательными для частных инвесторов [12].

Таким образом, если политика государства направлена на сохранение и развитие железнодорожного транспорта путем приватизации, она не может отказаться от контроля над ним и его поддержки. Хотя показатели работы государственных железных дорог в основном ниже, чем частных, нельзя однозначно говорить, что они хуже работают. Такое сравнение не всегда корректно это связано с выделением инфраструктуры и несовершенством расчетов сравнения.

Итак, анализируя опыт зарубежных стан в отношении применимости механизмов и методов организации (реорганизации), особенно актуальным в современных условиях представляется разработка комплекса задач по определению рациональных эксплуатационных параметров, способствующих повышению эффективности пригородных перевозок, в частности:

- расчет количества пригородных поездов для освоения пассажиропотока на конкретном участке;

- организация движения пригородных поездов с разной частотой, вместимостью пассажиров и количеством вагонов;

- определение показателей, характеризующих качество пригородных пассажирских перевозок и др.

\section{ВывоАы и преА^ожения}

На основе анализа научных работ и разработок по развитию пассажирских перевозок в пригородном сообщении можно сделать следующие заключения:

1. Следует отметить, что сейчас существует ряд научных трудов и разработок по реструктуризации и развития пассажирских перевозок, в том числе и в пригородном сообщении. Зарубежные и отечественные ученые обращают внимание на то, что в современных условиях для успешного функционирования железнодорожной отрасли и интеграции в международное социально-экономическое пространство нужно обеспечить:

- реструктуризацию структуры управления отраслью с целью четкого разграничения есте- 
ственно-монопольных и потенциально конкурентных видов хозяйственной деятельности, стимулирование конкуренции во втором случае и усиление государственного контроля в первом;

- сохранение преимуществ интегрированных систем - технологической целостности, управляемости и надежности;

- отказ от затратного принципа ценообразования на услуги субъектов естественных монополий, разделения тарифов на естественно-монопольную и конкурентную составляющие;

- полную организационную и финансовую прозрачность деятельности железнодорожных предприятий;

- недискриминационный доступ независимых производителей и потребителей к услугам железнодорожной отрасли в условиях эффективного антимонопольного регулирования;

- прекращение перекрестного субсидирования различных категорий потребителей.

2. Анализ моделей управления пригородными пассажирскими перевозками в странах мира показал, что, несмотря на различные подходы к структурной реформе пригородного сообщения, существуют определенные совместные действия, которые следует выполнить всем странам. К ним можно отнести выбор организационно-правовой формы субъекта хозяйствования - вновь созданные структуры управления пригородными перевозками.

3. На выбор организационно-правовой формы управления пригородными перевозками влияет ряд факторов:

- сохранение железнодорожного транспорта как единого производственно-технического комплекса и корпоратизация всех структур;

- сохранение государственного регулирования и контроля за деятельностью компаний, реализующих пригородные пассажирские перевозки;

- сохранение стабильности работы и безопасного функционирования пригородных пассажирских перевозок;

- сохранение социальной защиты работников железнодорожного транспорта;

- традиции и учет тенденций развития железнодорожного транспорта в каждой стране;
- удельный вес железнодорожного транспорта в общем объеме транспортных перевозок;

- степень развития рыночных условий в конкретной стране;

- скорость структурной реформы с учетом национальных особенностей характера деятельности кадров сферы и их готовности работать в рыночных условиях.

Для России очень важно учитывать симбиоз указанных факторов, так как это позволит железнодорожному транспорту страны постепенно и надежно интегрироваться в единую европейскую и мировую транспортную систему, исключив возможность негативных последствий структурной реформы.

4. На основе выполненного анализа отечественных и зарубежных научных трудов и практических разработок можно сделать вывод, что рекомендаций по созданию оптимального механизма управления пригородными пассажирскими перевозками, достойного полному использованию опыта конкретной страны, не существует, поскольку в каждой из них рыночные отношения находятся на разных уровнях развития. Кроме того, каждая из стран имеет свои национальные особенности рынка, степень развития железнодорожного транспорта, износ пассажирской инфраструктуры и подвижного состава, производительность труда и различную поддержку правительства страны.

Закономерности, приведенные выше, могут быть использованы при оценке эффективности прокладки в больших городах маятникового графика пригородного движения. Этот принцип также может быть использован при оценке рациональных вариантов размещения в графике движения пригородных поездов, следующих на ближние, средние и дальние расстояния. При современной организации пригородных перевозок железной дороги должны быть лучше удовлетворены требования и спрос потребителей. А с целью обеспечения приемлемой как для пассажиров, так и для перевозчика плотности пригородных поездов, целесообразно прокладывать нити графика таким образом, чтобы перед поездами дальнего назначения, отправлять поезда на более ближние назначения, что позволит улучшить показатели эффективности пригородных железнодорожных перевозок.

\section{ЛИТЕРАТУРА}

1. Агафонов Д. В. Государственное регулирование услуг железнодорожной инфраструктуры в условиях структурного преобразования отрасли (российский и мировой опыт) // Науковедение. 2017. Т. 9. № 2. С. 4-17.

2. Колин А.В., Роменский Д. Ю. Проблемы и перспективы развития мультимодальных пассажирских перевозок с использованием железнодорожного транспорта // Транспортное дело России. 2018. № 2. С. 104-107. 
3. Мозговая 0.0., Агафонов Д. В. Направления совершенствования механизһов государственного регулирования в целях привлечения и защиты инвестиций в инфраструктуру железнодорожного транспорта // Инфраструктурные отрасли экономики: проблемы и перспективы развития: сборник материалов Х Международной научно-практической конференции / Под общ. ред. С. С. Чернова. Новосибирск: Изд-во НГТУ, 2015. С. 145-153.

4. Савчук В.Б., Терешко И. В., Чернов Д. Д. Организация и финансирование пригородных железнодорожных пассажирских перевозок // Транспорт Российской Федерации. Журнал о науке, практике, экономике. 2016. № 2-3. С. 14-19.

5. Терешина Н.П., Флягина Т. А., Чуверина О.Г. Управление деятельностью пригородных пассажирских компаний // Транспортное дело России. 2019. № 2. C. 64-67.

6. Черемин Г.Д. Зарубежный опыт государственной политики в отношении железнодорожного транспорта // Вопросы политологии. 2018. Т. 8. № 3 (31). C. 104-111.

7. Щукин В. В. Зарубежный опыт регулирования тарифов на железнодорожные перевозки // Транспортное дело России. 2014. № 2. С. 99-102.

8. Adelé S., Tréfond-Alexandre S., Dionisio C., Hoyau P. A. Exploring the behavior of suburban train users in the event of disruptions // Transportation Research Part F: Traffic Psychology and Behaviour. 2019. Vol. 65. P. 344-362.

9. Caroline H., Yves A. Errac Roadmap WP03: Urban, Suburban and Regional Rail and Urban Mobility // Procedia — Social and Behavioral Sciences. 2012. Vol. 48. P. 2284-2294.

10. Kim H., Sultana S., Weber J. A geographic assessment of the economic development impact of Korean high-speed rail stations // Transport Policy. 2018 . Vol. 66. P. 127-137.

11. Li X., Yang T., Shi Q. Applicative Suburban Line Pattern of Urban Rail Transit in China // Procedia — Social and Behavioral Sciences. 2013. Vol. 966. P. 2260-2266.

12. Piner D., Condry B. International best practices in managing unplanned disruption to suburban rail services // Transportation Research Procedia. 2017. Vol. 25. P. 4403-4410.

13. Rahman S., Balijepalli C. Understanding the determinants of demand for public transport: Evidence from suburban rail operations in five divisions of Indian Railways // Transport Policy. 2016. Vol. 48. P. 13-22.

14. Zhou L., Liu Yu, Liu Ying. Research on the Spatial-System-Based Rail Transit Systems of the World Cities // Procedia Engineering. 2016. Vol. 137. P. 699-708.

15. 06 утверждении Транспортной стратегии Российской Федерации на период до 2030 года (с изменениями на 12 мая 2018 года) // Техэксперт. [Электронный ресурс]. Режим доступа: http://docs.cntd.ru/document/902132678 (Дата обращения: 28.03.2020).

16. Транспорт России. Информационно-статистический бюллетень. Январь — июнь 2019 года // Министерство транспорта Российской Федерации. [Электронный ресурс]. Режим доступа: https://www.mintrans.ru/documents/7/10141 (Дата обращения: 29.03.2020).

17. Распоряжение Правительства РФ от 19.05.2014 N857-р «0б утверждении Концепции развития пригородных пассажирских перевозок железнодорожным транспортом» // Консультант Плюс. [Электронный ресурс]. Режим доступа: http://www.consultant.ru/document/cons_doc_LAW_163361/ (Дата обращения: 28.03.2020). 